\title{
MANAJEMEN PELAYANAN TERPADU SATU PINTU SEBAGAI UPAYA PENINGKATAN LAYANAN ADMINISTRASI DI KANTOR KEMENTERIAN AGAMA KABUPATEN TUBAN
}

\author{
Eka Dana Margi Saputra, Sayyidah Sa'id, Shopa Marwati, Lili Nur A \\ UIN Sunan Ampel, Surabaya - Indonesia | ekadana57@gmail.com
}

\begin{abstract}
Abstrak: Penelitian ini bertujuan menjelaskan pelayanan terpadu satu pintu berupa upaya peningkatan layanan administrasi dari segi perencanaan, pelaksanaan, dan evaluasi. Layanan administrasi berbetuk dokumen resmi yang dibutuhkan masyarakat. Selain itu, guna mengetahui peran kordinator pelayanan terpadu satu pintu (PTSP) kantor kementerian agama kabupaten tuban. Deskriptif kualitatif sebagai pendekatan penelitian. Subjek dari penelitian ini adalah kordinator, dan dua staff PTSP. Penelitian ini menggunakan tek analisisi berupa reduksi data, penyajian data dan penarikan kesimpulan. Setelah diadakan penelitian, dapat disimpulkan bahwa layanan administrasi dapat ditingkatkan dengan perencanaan yang terstruktur, pelaksanaan yang sesuai dengan juknis PTSP, dan evaluasi rutin dari kordinator.
\end{abstract}

Keywords: pelayanan, satu pintu, adminsistrasi, terpadu

\section{Pemdahuluan}

Kantor merupakan tempat berlangsungnya kegiatan pengelolaan tata usaha.1 Khususnya kantor pemerintahan. Kantor pemerintahan sangat vital perannya. Karena, berperan sebagai penyedia pelayanan keperluan masyarakat. Peran tersebut merupakan sebuah komitmen yang harus dipenuhi kepada

\footnotetext{
${ }^{1}$ Zainudin, Wafi Ali Hajaj dan Abdul Haq, "Manajemen Perkantoran Modern," Islamica Akademika: Jurnal Pendidikan \& Keislaman 3, No. 1: 78.
} 
masyarakat.2 Untuk mencapai pelayanan kantor yang prima ma ka munculah gagasan ide penyelenggaraan pelayanan terpadu satu pintu. Ide tersebut muncul, dikarenakan banyaknya sub bagian yang ada di dalam kantor tidak memungkinkan untuk menemui satu per-satu masyarakat yang sedang membutuhkan pelayanan.

Pelayanan terpadu satu pintu menurut keputusan Menteri agama republik Indonesia nomer 90 tahun 2018 adalah kegiatan dalam rangka pemenuhan kebutuhan pelayanan masyarakat.3 Definisi lain dari pelayanan terpadu satu pintu adalah kegiatan penyelenggaran jasa perizinan dan non perizinan, pengelolaanya dimulai dari proses permohonan sampai penerbitan ijin arsip pada satu tempat.4 Merujuk pada satu tempat maka PTSP merupakan layanan pertama yang dikunjungi masyarakat di kantor sebelum kekebutuhan masyarakat.

Tujuan dari pelayanan terpadu satu pintu diungkapkan melalui asas dan prinsip yaitu keterbukaan dan mudah diakses pada semua pihak, sesuai dengan undang-undang berlaku dan dapat dipertanggungjawabkan, kesamaan hak (tidak membedakan masyarakat / diskriminatif )5 dan partisipatif (perhatian dan kepedulian terhadap masyarakat)6.

${ }^{2}$ Rita Yuningsih, "Kualitas Pelayanan Publik di Kantor Perwakilan Pemerintah Daerah Kabupaten Tolitoli Kota Palu," Jurnal Katologis 4, No. 8 (Agustus 2016): 175.

${ }^{3}$ Keputusan Menteri Agama Republik Indonesia Nomor 90 Tahun 2018 tentang Petunjuk Pelaksanaan Penyelenggaraan Pelayanan Terpadu Kementerian Agama.

${ }^{4}$ Suhartoyo, "Implementasi Fungsi Pelayanan Publik dalam Pelayanan Terpadu Satu Pintu (PTSP)," Administrative law \& Governance Journal 2, No. 1 (Maret 2019): 149.

${ }^{5}$ Imelda, Nur Fitriyah, dan Enos Paselle, “Efektivitas Pelayanan Terpadu Satu Pintu Terhadap Penyerpan Investasi di Kalimantan Timur (Studi Kasus Badan Perijinan dan Penanaman Modal Daerah," Jurnal Administrative Reform 2, No. 3 (September 2014): 412.

${ }^{6}$ Dinda Hayyi Nur Azizah, Afifudin, dan Suyeno, "Implementasi Pelayanan Publik pada PTSP dalam Mempermudah Akses Pelayanan Publik (Studi Kasus Kantor Kementerisan Agama Kab. Madiun)," Jurnal Respon Publik 14, No. 1 (2020): 14. 
Pelayanan terpadu satu pintu atau biasa disingkat PTSP memiliki tiga bidang layanan yaitu layanan jasa, barang dan administrasi. Berhubung penelitian ini berfokus pada layanan administrasi maka hanya dijelaskan perihal layanan administrasi. Layanan administrasi adalah layanan berupa surat menyurat, tata laksana dokumen pengarsipan dan penomoran surat. Agar kegiatan layanan administrasi berjalan sesuai dan baik maka diperlukan manajemen pada pelayanan terpadu satu pintu.

Adapun beberapa pendapat para ahli perihal manajemen. Stephan P. Robbins berpendapat manajemen adalah serangkaian ativitas kerja yang melibatkan kordinasi dan pengawasan terhadap orang lain sehingga pekerjaan tersebut diselesaikan dengan efektif dan efesien.7 Menurut Terry manajemen ialah proses terperinci tentang perencanaan, pengorganisasian, pelaksanaan, dan pengendalian suatu organisasi untuk mencapai tujuan bersama dengan menggunakan manusia sebagai sumber daya. 8

Pendapat dari A.F. Stoner mirip dengan Terry yaitu manajemen merupakan proses perencanaan, pengorganisasian, pengarahan dan pengawasan usaha organisasi agar mencapai tujuan yang telah ditetapkan.9 Jadi, dapat disimpulkan bahwa manajemen pelayanan terpadu satu pintu adalah proses perencanaan, pengorganisasian, pelaksanaan, dan evaluasi dalam penyelenggaraan proses perizinan dan non perizinan.

Tahapan kegiatan pelayanan terpadu satu pintu untuk mencapai tujuan yang ditetapkan diawali dengan proses perencanaan dan pengorganisasian yaitu mencangkup struktur organisasi, pendelegasian wewenang dan alokasi anggaran. Pelaksanaan yaitu tindakan menjalankan program sesuai dengan rencana yang telah dibuat. Evaluasi yaitu penilaian terhadap hasil

\footnotetext{
${ }^{7}$ Stephen P. Robbins dan Mary Coulter, Management, thirteenth edition trans. Bob Sabran dan Devri B. P (Jakarta: Erlangga, 2016), 14.

${ }^{8}$ Siti Farikhah, Manajemen Lembaga Pendidikan (Temanggung: Aswaja Pressindo, 2015), 2.

${ }^{9}$ Imam Heryanto dan Totok Triwibowo, Manajemen Proyek Berbasis Teknologi Informasi: Mengelola Proyek Secara Sistematis Menggunakan Microsoft Project (Bandung: Informatika Bandung, 2016), 14.
} 
kinerja. Harapannya dengan adanya pengelolaan manajemen yang baik pada pelayananan terpadu satu pintu, layanan yang diberikan kepada masyarakat sesuai dengan prinsip senada dengan penelitian yang berjudul "Implementasi Fungsi Pelayanan Publik dalam Pelayanan Terpadu Satu Pintu".

Kantor Kementerian Agama Kabupaten Tuban adalah Kantor yang mengurusi kebutuhan masyarakat yang berhubungan dengan Agama yang memiliki visi "Terwujudnya masyarakat kabupaten Tuban yang taat beragama, inklusif, toleran, rukun, berpendidikan, mandiri, sejahtera, lahir dan batin." salah satu misinya adalah "mewujudkan tata kelola kepemerintahan yang profesional, integeritas, bersih dan melayani" merupakan upaya kementerian kabupaten Tuban untuk membangun pelayanan terpadu satu pintu yang terkelola baik dan efektif maupun efisien dalam melayani masyarakat.

Latar belakang penelitian ini berfokus pada pengelolaan PTSP dalam layanan administrasi. Oleh karena itu, penelitian yang akan dilakukan berjudul manajemen pelayanan terpadu satu pintu sebagai upaya peningkatan layanan administrasi di kantor kementerian agama kabupaten Tuban. Dengan rumusan masalah; a) bagaimana perencanaan pelayanan terpadu satu pintu? b) bagaimana pelaksanaan pelayanan terpadu satu pintu? c) bagaimana evaluasi pelayanan terpadu satu pintu sebagai upaya peningkatan layanan administrasi?.

Tujuan dari penelitian ini untuk mengetahui sejauh mana kegiatan pelayanan terpadu satu pintu di Kementerian Agama Kabupaten Tuban, selain itu juga untuk mengetahui peran kordinator dalam pelayanan terpadu satu pintu.

\section{Metodologi}

Deskriptif kualitatif sebagai pendekatan dari penelitian ini. Pada pelaksanannya subjek yang diamati adalah kordinator dan staf pelayanan terpadu satu pintu. Waktu pengamatan terhitung mulai tanggal 19 agustus 2020 - 14 oktober 2020. Penelitian ini berlokasi di kantor Kementerian Agama Kabupaten Tuban. Pengambilan data menggunakan, observasi, wawancara dan dokumentasi. 
Data yang terkumpul ialah data perencanaan, pengorganisasian, pelaksanaan, dan evaluasi yang dilakukan kordinator dan staf pada pelayanan terpadu satu pintu. Penelitian ini menggunakan analisis data yang sistematis dan logis, analisis data dilakukan sejak kedataangan peneliti hingga akhir. Analisis data menggunakan metode Huberman yaitu reduksi data, penyajian data, dan penarikan kesimpulan.10

\section{Hasil dan Pembahasan}

Perencanaan dan Pengorganisasian Pelayanan Terpadu Satu Pintu

Perencanaan adalah kegiatan paling penting, karena perencanaan berisi sebuah rencana tentang perkiraan yang akan terjadi. Apabila seorang perencana dalah memperkirakan rencana maka sama saja merencanakan sebuah kegagalan. Begitu pula pada pelayanan terpadu satu pintu di kantor kementerian agama kabupaten Tuban, sangat diperlukan perencanaan yang matang. Pelayanan terpadu satu pintu dirilis pada tanggal 7 maret 2020, terbilang sangat baru dan baru terlaksana 7 bulan sampai pada September ini. Hal ini muncul setelah kantor wilayah kementerian agama provinsi mewajibkan seluruh kantor kementerian agama di Jawa Timur memiliki pelayanan terpadu satu pintu. Semata-mata tujuan adanya pelayanan terpadu satu pintu adalah kepuasan masyarakat, dengan kemudahan, keterjangkauan dan kecepatan pelayanan yang ada pada kantor kemeterian agama khususnya di kabupaten Tuban.

Pembentukan awal pelayanan terpadu satu pintu dengan instruksi bapak Drs. Sahid, M.M selaku kepala membentuk struktural organisasi. Beliau menunjuk ibu Laidia Maryati, S.Ag, MA sebagai kordinator, ibu Lilik Ernawati dan Nuril 'irnina sebagai staf. Perencanaan yang dibuat tidak terlalu khusus hanya sesuai dengan Keputusan Menteri Agama Republik Indonesia Nomor 90 Tahun 2018 dan pada intinya sebagai pelayanan publik, yang selayaknya melayani masyarakat. Standar operasional yang digunakan pada layanan admisnistrasi dikelompokan dua macam yaitu tentang persuratan, apabila ada surat masuk atau keluar tahap

${ }^{10}$ Sugiyono, Metode Penelitian Kualitatif, Kuantitatif dan R\&D (Bandung: Alfabeta, 2009), 246. 
awal melalui PTSP mengisi buku tamu selanjutnya di teruskan ke Kepala Lembaga setelah disetujui apabila ditujukan pada seksi maka diteruskan kesana dan terkahir Kembali ke PTSP untuk siserahkan pada masyarakat berkepentingan. Kedua tentang legalisir atau pengesahan izasah, tahap awal menuju PTSP setelah itu mengisi buku tamu, max legalisir 10 kali dan 2 lembar diperuntukan kementerian agama sebagai arsip setelah itu PTSP memberikan tanda terima berupa tiket untuk pengambilan. Selanjutnya diteruskan ke Kepala Lembaga untuk disahkan dan Kembali pada PTSP, masyarakat mengambill dengan menujukan tiket tersebut.

Tugas dari kordinator adalah mengatur strategi, program penyelenggaraan PTSP sampai pada perumusan kebijakan, melaksanakan pengamatan dan bimbingan, mengkordinasikan tugas dan fungsi staf, bertanggung jawab penuh atas penyelenggaran PTSP, menghimpun dan menggunakan SDM yang ada secara efektif dan efisien dan melaporkan secara periodic kepada Menteri agama. Tugas dari staff melakukan rekomendasi lanjutan, melakukan surat-menyurat, melakukan tata Kelola dokumen, pengarsipan dan penomoran surat dan mengatur tata usaha, melakukan penghimpunan data layanan, mempublikasikan pelaksanaan PTSP.

Selain itu penyiapan sarana dan prasarana untuk mendukung efektif dan efisiennya PTSP perlu diperhatikan. Dengan kecanggihan teknologi pleayanan PTSP di kantor kementerian agama kabupaten Tuban menggunakan aplikasi bernama aplikasi manajemen surat (untuk persuratan) dan PTSP kemeterian agama kabupaten tuban (untuk pencetakan tiket tanda terima). Maka membutuhkan komputer, scanner dan printer. Selain itu perlu di desain senyaman mungkin tempat PTSP agar masyarakat betah dan nyaman Ketika berkunjung. Alokasi anggaran untuk PTSP bekerja sama dengan pihak Bank BRI karena, tidak disediakan DIPA untuk PTSP.

\section{Pelaksanaan Pelayanan Terpadu Satu Pintu}

Pelayanan terpadu satu pintu terdapat tiga tempat duduk, dua diperuntukan staf dan satu di tengah untuk kordinator. Dua 
computer diletakan kanan dan kiri, sebelah kiri sementara diperuntukan untuk aplikasi AMS dan sebelah kanan untuk aplikasi pencetak tiket agar efektif dan efisien. Akantetapi tidak menutup kemungkinan kedua computer itu digunakan untuk AMS atau sebaliknya tergantung dari insensitas dari surat dan masyarakat melegalisisr izasah. Terhitung per-harinya 5 surat masuk atau bisa lebih, jikalau diakumulasikan per-minggu bisa mencapai 20-an lebih. Sedangkan masyarakat melegalisir belum bisa dipastikan per harinya, karena tidak mesti. Apabila dihitung per-minggunya bisa sampai 15 -an orang atau bisa lebih banyak jumlahnya.

Macam surat berupa dari luar Lembaga berupa undangan, pendirian, pengajuan proposal, dan penawaran kerja sama. Apabila ada surat masuk, surat diterima oleh staf PTSP di scan dan dimasukan ke dalam aplikasi AMS, setelah itu dicetak lembar disposisi, di teruskan ke Kepala Lembaga setelah di setujui (apabila surat di tujukan ke Kepala Lembaga maka berhenti di situ biasanya berupa undangan, pengajuan proposal dan jalinan kerja sama) di antar staf ke seksi apabila di tujukan ke situ (biasanya berupa pendirian). Apabila surat keluar, dari seksi menuju PTSP dan diantar pada Lembaga setelah disahkan Kembali pada PTSP dan diserahkan ke seksi terkait hal itu sama apabila ada surat naik / yang perlu disetujui oleh Kepala Lembaga.

Sedangkan legalisir ijazah alurnya awal menuju PTSP setelah itu staf mengecek kelengkapan berkas, setelah dicek mencetak tiket tanda terima melalui aplikasi, menyerahkan pada masyarakat (bisa ditunggu atau ditinggal), di serahkan ke Kepala Lembaga untuk di sah kan dan Kembali pada PTSP, masyarakat bisa mengambilnya dengan menyerahkan bukti tiket tanda terima. Kursi tengah yang kosong tersebut di tempati oleh kordinator yang bertugas mengawasi staf apabila tidak mengetahui kode klasifikasi surat atau perihal kebijakan lainya. Selain itu kordinator mencatat dan mengingatkan staf apabila melakukan keteledoran dalam bertugas. Dikarenakan jabatan yang ganda oleh bu laidia selaku kordinator dan humas beliau tidak selalu menempati kursi tersebut. Pada waktu-waktu memang tidak ada kesibukan humas maka beliau 
bertugas di sana. Tetap pengawasan jarak jauh dilakukan melalui jejaring sosial.

\section{Evaluasi Pelayanan Terpadu Satu Pintu}

Setiap pelaksanaan kegiatan pelayanan terpadu satu pintu tentunya memerlukan evaluasi guna mengukur sejauh mana ketercapaian rencana pada pelaksanaannya. Evaluasi dapat dilaksanakan pada saat pelaksaanan berlangsung dan pada akhir pelaksanaan. Hasil dari evaluasi adalah sebuah kebijakan baru yang lebih baik pada sebelumnya. Demikian pula yang diterapkan di kantor kementerian agama kabupaten Tuban terutama yang berkaitan pada pelayanan terpadu satu pintu. Evaluasi dilakukan secara internal antara kordinator dengan staf pada saat kegiatan pelayanan berlangsung dan pada saat kegiatan pelayanan berakhir. Evaluasi yang diterpkan cenderung longgar dan bertumpu pada kondisi darurat atau pada saat dibutuhkan.

Sedangkan evaluasi eksternal adalah pada saat pengawas dari kantor wilayah berkunjung dengan membawa draft penilaian PTSP. Penilaian berdasarkan peraturan terbaru kementerian agama tentang pelayanan terpadu satu pintu.

\section{Kesimpulan}

Simpulan berdasarkan penelitian ini adalah bahwa Perencanaan melibatkan Kepala Lembaga, kordinator dan dua staf pelayanan terpadu satu pintu yang membahas tugas, struktur, dan alur SOP.

Pelaksanaan sudah baik sesuai dengan rencana, akan tetapi dwi fungsi yang diemban kordinator bisa menurunkan efektifitas dan efisiensi PTSP, karena kondisional dalam pengawasan staf.

Evaluasi ada dua macam berupa internal dilakukan oleh kordinator di saat kegiatan pelayanan terpadu satu pintu berlangsung maupun di akhir. Eksternal dilakukan oleh pengawas kantor wilayah provinsi jawa timur dengan membawa draft penilaian.

Berdasarkan penelitian ini disarankan agar Kordinator lebih difokuskan dengan hanya satu jabatan agar lebih fokus dan maksimal pada pelayanan terpadu satu pintu. Pemberlakuan evaluasi rutin oleh kordinator. Staf lebih menghafal dan faham 
terkait kode klasifikasi surat dan Lebih partisipatif pada masyarakat.

\section{References}

Azizah, Dinda Hayyi Nur Afifudin, dan Suyeno. “Implementasi Pelayanan Publik pada PTSP dalam Mempermudah Akses Pelayanan Publik (Studi Kasus Kantor

Kementerisan Agama Kab. Madiun)," Jurnal Respon Publik 14, No. 1 (2020): 14.

Farikhah, Siti. Manajemen Lembaga Pendidikan. Temanggung: Aswaja Pressindo, 2015.

Heryanto, Imam dan Totok Triwibowo. Manajemen Proyek Berbasis Teknologi Informasi: Mengelola Proyek Secara Sistematis Menggunakan Microsoft Project. Bandung: Informatika Bandung, 2016.

Imelda, Nur Fitriyah, dan Enos Paselle. "Efektivitas Pelayanan Terpadu Satu Pintu Terhadap Penyerpan Investasi di Kalimantan Timur (Studi Kasus Badan Perijinan dan Penanaman Modal Daerah," Jurnal Administrative Reform 2, No. 3 (September 2014): 412.

Keputusan Menteri Agama Republik Indonesia Nomor 90 Tahun 2018 tentang Petunjuk Pelaksanaan Penyelenggaraan Pelayanan Terpadu Kementerian Agama.

Robbins, Stephen P. dan Mary Coulter. Management, thirteenth edition trans. Bob Sabran dan Devri B. P. Jakarta: Erlangga, 2016.

Sugiyono. Metode Penelitian Kualitatif, Kuantitatif dan R\&D. Bandung: Alfabeta, 2009.

Suhartoyo. "Implementasi Fungsi Pelayanan Publik dalam Pelayanan Terpadu Satu Pintu (PTSP)," Administrative law \& Governance Journal 2, No.

1 (Maret 2019): 149. 
Yuningsih, Rita. "Kualitas Pelayanan Publik di Kantor Perwakilan Pemerintah Daerah Kabupaten Tolitoli Kota Palu," Jurnal Katologis 4, No. 8 (Agustus 2016): 175.

Zainudin, Wafi Ali Hajaj dan Abdul Haq. "Manajemen Perkantoran Modern," Islamica Akademika: Jurnal Pendidikan \& Keislaman 3, No. 1: 78. 